\title{
Treatment of recurrent stress urinary incontinence in women: comparison of treatment results for different surgical techniques
}

\author{
Ausra Cerniauskiene $^{1}$, Marija Barisiene ${ }^{2}$, Feliksas Jankevicius ${ }^{1}$, Gediminas Januska ${ }^{3}$ \\ ${ }^{1}$ Centre of Urology, Vilnius University, Faculty of Medicine, Vilnius, Lithuania \\ ${ }^{2}$ Centre of Urology, Vilnius University Hospital Santariskiu Klinikos, Vilnius, Lithuania \\ ${ }^{3}$ Vilnus University, Residency Centre, Vilnius, Lithuania
}

Videosurgery Miniinv 2014; 9 (2): 239-245

DOI: $10.5114 /$ wiitm.2014.43025

\begin{abstract}
Introduction: There is still no consensus on which surgical technique is the most effective for female recurrent stress urinary incontinence after the initial surgery.

Aim: To compare the long-term treatment outcomes of Burch colposuspension operation, transobturator tape implantation (TOT) and tension-free vaginal tape (TVT) procedures performed for female recurrent stress urinary incontinence after the initial surgery.

Material and methods: A retrospective study was performed on 45 women operated on for recurrent stress urinary incontinence after the initial surgery. Depending on the surgical approach, the patients were divided into three groups: group I $(n=19)$ - Burch colposuspension operation, group II $(n=16)-T O T$, and group III $(n=10)-T V T$ operation was performed. The treatment results were assessed using the UDI-6 (Urogenital Distress Inventory) and IIQ-7 (Incontinence Impact Questionnaire) short form questionnaires. We included one additional question: Is the patient satisfied with the treatment outcome? We classified the urinary continence results after surgery as good when patients were cured or improved, and as bad when the treatment failed.

Results: Good urinary continence results were observed in $84.2 \%$ of patients in group I, $93.8 \%$ of patients in group II, and $90 \%$ of patients in group III. $68.4 \%$ of patients in group I, $81.3 \%$ of patients in group II, and $90 \%$ of patients in group III were satisfied with the treatment outcomes.

Conclusions: Burch colposuspension operation, TOT and TVT procedures performed for the female recurrent stress urinary incontinence treatment are effective and show similar good urinary continence results and similar number of patients satisfied with the treatment outcomes.
\end{abstract}

Key words: surgery, quality of life, urinary incontinence, suburethral sling, treatment outcome.

\section{Introduction}

Female stress urinary incontinence is defined as any involuntary leakage of urine during physical activity, sneezing, or coughing [1, 2]. It is diagnosed in more than 1 in 4 adult women and approximately half of all women suffering from urinary incontinence $[3,4]$.

Since the 1960s, the Burch colposuspension operation has been a standard treatment method for female stress urinary incontinence. Long-term follow-up suggests a durable outcome with cure rates of $82 \%$ after 5 years and $69 \%$ after 12 years. The reoperation rate due to persistent urinary incontinence for patients who underwent the Burch colposuspension operation ranged from 4.2 to 5.5 per 1000 women-years [3, 5].

In 1996, Ulmsten described a new minimal invasive technique, a tension-free vaginal tape (TVT) for 
urinary incontinence treatment [6]. This technique soon became very popular because of its quite low complication rate, good results, and possibility to perform it in the outpatient department. The recently published prospective randomized studies report the TVT success rate ranging from $80 \%$ to $95 \%$ with a longer than 5 -year follow-up $[1,7,8]$.

In 2001, the French urologist Delorme described another minimal invasive technique, transobturator tape implantation (TOT) [6]. This operative technique allowed reduction of the risk of bladder and bowel perforation and major vascular injury that can occur with TVT [8-10]. The published data reported the TOT success rate ranging from $80.5 \%$ to $96 \%$ [1].

Currently, the suburethral sling is the gold standard treatment for female stress urinary incontinence [11].

There are lots of discussions in the literature as to which of the operative techniques for female recurrent stress urinary incontinence is the most effective and the safest; however, there is no consensus on this issue.

\section{Aim}

The aim of the study was to compare the longterm treatment outcomes of Burch colposuspension operation, TOT and TVT procedure performed for female recurrent stress urinary incontinence after the initial surgery.

\section{Material and methods}

A retrospective study was performed on 45 women operated on due to recurrent stress urinary incontinence after the initial surgery at the Urology Centre of the Vilnius University Hospital "Santariskiu Klinikos" in the period from January 2003 to November 2012. The initial surgery for stress urinary incontinence was vaginoplasty, Burch colposuspension operation, TVT, or TOT operation. The recurrent stress urinary incontinence diagnosis was corroborated by physical examination, and all of the patients had a positive cough test. Also, a urogynecological examination, urinalysis, urine culture, urogenital ultrasound and the measure of postvoid residual urine, and colpocystograms were performed. Due to technical problems, urodynamic testing was not performed in all cases. The surgery for recurrent stress urinary incontinence and the further follow-up were performed by one experienced urologist. According to the surgical technique that was chosen for recurrent stress urinary incontinence treatment, all the patients were divided into three groups: in group I $(n=19)$ Burch colposuspension operation, in group II $(n=16)$ TOT operation, and in group III $(n=10)$ TVT operation was performed. All the three groups were compared according to age, body mass index (BMI), time between initial and second surgery, number of deliveries, presence of hysterectomy, and perineal ruptures in the past. All the patients were assessed at 1 month postoperatively, at which time the cough test, postvoid residual urine volume, and procedure-related complications were evaluated. The long-term treatment outcomes were evaluated after 6 months to 9 years after the second surgery, 4 years being the median. The median time of treatment outcomes evaluation was 5 years in group I, 3 years in group II, and 1 year in group III. The UDI-6 and IIQ-7 questionnaires short forms [12, 13] were sent to the patients to evaluate the urine continence results and the quality of life after the surgery. Also, we included one additional question: Is the patient satisfied with the treatment outcome? The urine continence results were assessed as cured if the patient was completely continent; improved if partial urinary incontinence remained after the surgery; and failed if the degree of urinary incontinence remained the same or was even worse compared with the condition before the surgery. We classified it as a good continence result when the patients were cured or improved, and as a bad result when the treatment failed.

\section{Statistical analysis}

We used SPSS version 17.0 for Windows for statistical analysis. The one way ANOVA, independent sample $t$-test, and crosstabs were used to compare the groups by analyzed demographic and clinical characteristics and to compare the treatment outcomes between the three patient groups and to assess the risk factors that could have influenced the numbers of satisfied and dissatisfied patients. Values of $p<0.05$ were considered statistically significant.

\section{Results}

A retrospective study was performed on 45 women operated on due to recurrent stress urinary incontinence after the initial surgery. As a second surgery Burch colposuspension operation, TOT or TVT pro- 
cedure was performed. The median time from the initial surgery until the second surgery for the recurrent stress urinary incontinence was 8.1 (0.17-29) years. The demographics and clinical characteristics of the 3 patients groups are summarized in Table I. The degree of urinary incontinence before the second surgery in each group is shown in Table II. Comparing the groups by age, BMI, number of deliveries, previous perineal ruptures, presence of hysterectomy in the past, the time between initial and second surgery, and the degree of urinary incontinence before the second surgery, there was no statistically significant difference $(p>0.05)$.

We analyzed the answers to UDI-6 and IIQ-7 questionnaire short forms to evaluate the urine continence results and the quality of life after the surgery.

The assessment of UDI-6 short form questionnaire is as follows: $73.7 \%$ of patients in group I $(n=$ $19), 68.8 \%$ of patients in group II $(n=16)$, and $100 \%$ of patients in group III $(n=10)$ had no irritative bladder symptoms after the surgery at all, or these symptoms were minimal and had no negative impact on the quality of life; $84.2 \%$ of patients in group I $(n=19), 93.8 \%$ of patients in group II $(n=16)$, and $90 \%$ of patients in group III $(n=10)$ were completely continent or had partial urinary incontinence; $57.9 \%$ of patients in group I ( $n=19), 93.8 \%$ of patients in group II $(n=16)$, and $90 \%$ of patients in group III $(n=10)$ did not complain of bladder obstructive symptoms and did not feel discomfort while urinating, or these symptoms were minimal and had no negative impact on the quality of life. The answers to the UDI-6 short form questionnaire are summarized in Table III. We found that women in group I statistically significantly more often complained of bladder obstructive symptoms and discomfort on urinating than women in group II and group III ( $p=0.023)$.

The assessment of the IIQ-7 short form questionnaire is as follows: the urinary incontinence had no

Table I. Demographic and clinical characteristics of patients in each group

\begin{tabular}{|lcccc|}
\hline Variables & Group I $(n=19)$ & Group II $(n=16)$ & Group III $(n=10)$ & Value of $p$ \\
\hline Age, mean \pm SD [years] & $56.21 \pm 7.43$ & $62.94 \pm 6.82$ & $60.70 \pm 12.86$ & 0.079 \\
\hline Body mass index, mean \pm SD $\left[\mathrm{kg} / \mathrm{m}^{2}\right]$ & $30.27 \pm 5.86$ & $29.38 \pm 4.28$ & $29.18 \pm 3.99$ & 0.823 \\
\hline Number of deliveries, median (min.; max.) & $2(0 ; 5)$ & $2(0 ; 2)$ & $2(0 ; 3)$ & 0.152 \\
\hline Previous perineal rupture, $n(\%)$ & $15(78.9)$ & $9(56.3)$ & $8(80.0)$ & 0.263 \\
\hline Previous hysterectomy, $n(\%)$ & $3(15.8)$ & $5(31.3)$ & $2(20.0)$ & 0.539 \\
\hline $\begin{array}{l}\text { Time between initial and second surgery, } \\
\text { median (min.; max.) [years] }\end{array}$ & $8(0.17 ; 29)$ & $6(0.33 ; 29)$ & $2(0.33 ; 13)$ & 0.074 \\
\hline
\end{tabular}

$S D$ - standard deviation

Table II. The degree of urinary incontinence before the second surgery in each group

\begin{tabular}{|lcccc|}
\hline Degree of urinary incontinence & Group I $(n=19)$ & Group II $(n=16)$ & Group III $(n=10)$ & Value of $p$ \\
\cline { 1 - 4 } II, $n(\%)$ & $9(47.4)$ & $7(43.8)$ & $5(50.0)$ & 0.950 \\
\cline { 1 - 3 } III, $n(\%)$ & $10(52.6)$ & $9(56.3)$ & $5(50.0)$ & \\
\hline
\end{tabular}

Table III. Summary of answers to UDI-6 questionnaire short form

\begin{tabular}{|lccccccc|}
\hline Symptoms & \multicolumn{2}{c}{ Group I $(n=19)$} & \multicolumn{2}{c}{ Group II $(n=16)$} & \multicolumn{2}{c|}{ Group III $(n=10)$} & Value \\
\cline { 2 - 6 } & $\begin{array}{c}\text { No or minimal } \\
(\%)\end{array}$ & Yes $(\%)$ & $\begin{array}{c}\text { No or minimal } \\
(\%)\end{array}$ & Yes $(\%)$ & $\begin{array}{c}\text { No or minimal } \\
(\%)\end{array}$ & Yes $(\%)$ & 0.150 \\
\hline Irritative & 73.7 & 26.3 & 68.8 & 31.2 & 100.0 & 0 & 0.665 \\
\hline Urinary incontinence & 84.2 & 15.8 & 93.8 & 6.2 & 90.0 & 10.0 & 0.0 \\
\hline Obstructive/discomfort & 57.9 & 42.1 & 93.8 & 6.2 & 90.0 & 10.0 & 0.023 \\
\hline
\end{tabular}


negative impact on physical activity in $84.2 \%$ of patients in group I $(n=19), 87.5 \%$ of patients in group II $(n=16)$, and $90 \%$ of patients in group III $(n=10)$; the urinary incontinence had no negative impact on travelling in $84.2 \%$ of patients in group I $(n=19)$, $81.3 \%$ of patients in group II $(n=16)$, and $90 \%$ of patients in group III $(n=10)$; the urinary incontinence had no negative impact on communication in $89.5 \%$ of patients in group I $(n=19), 81.3 \%$ of patients in group II $(n=16)$, and $100 \%$ of patients in group III $(n=10)$; the urinary incontinence had no negative impact on emotional status in $84.2 \%$ of patients in group I $(n=19), 75.0 \%$ of patients in group II $(n=$ $16)$, and $90 \%$ of patients in group III $(n=10)$. The answers to the IIQ-7 short form questionnaire are summarized in Table IV. We did not find any statistically significant difference between the groups.

We assessed the patients' answers to the additional question: Are the patients satisfied with the treatment outcomes? $68.4 \%$ of patients in group I $(n=19), 81.3 \%$ of patients in group II $(n=16)$, and $90 \%$ of patients in group III $(n=10)$ were satisfied with the treatment outcomes (Table V).

The assessment of the relationship between number of patients satisfied with the treatment outcomes and the estimated risk factors showed that where time between the initial and second surgery was shorter, there were more women satisfied with treatment outcomes ( $p=0.001$ ) (Table VI).

The mean hospitalization stay was 5.76 days (SD 2.52). We had no intraoperative complications registered. During the early postoperative period void- ing difficulty was present in $4(8.88 \%)$ women: in 3 (33.33\%) women after the TVT procedure (group 3) and in $1(6.25 \%)$ woman after the TOT procedure (group 2). Two women required intermittent catheterization, which lasted 5 and 6 days, respectively. In two cases the suburethral sling was pulled down on the $8^{\text {th }}$ and $3^{\text {rd }}$ postoperative day, respectively.

Patients were assessed at 1 month after the second surgery. We had no late postoperative complications revealed.

Based on our study, we may conclude that the Burch colposuspension operation, TOT and TVT procedures performed for female recurrent stress urinary incontinence treatment are effective and show similar good urinary continence results: $84.2 \%$ in group I, $93.8 \%$ in group II, and $90 \%$ in group III. There were equal numbers of patients satisfied with the treatment outcomes in the groups but when the time between the initial and second surgery was shorter, there were more patients satisfied with the treatment outcomes.

The assessment of UDI-6 questionnaire short form has shown that the women after the Burch colposuspension operation (group I) performed due to recurrent stress urinary incontinence statistically significantly more often complained of bladder obstructive symptoms and discomfort on urination compared with the women after minimal invasive surgical procedures (group II and group III).

While we have found almost equal good treatment outcomes of the Burch colposuspension operation, TOT or TVT procedure performed for female

Table IV. Summary of answers to IIQ-7 questionnaire short form

\begin{tabular}{|lccccccc|}
\hline Activity/status & \multicolumn{2}{c}{ Group I $(n=19)$} & \multicolumn{2}{c}{ Group II $(n=16)$} & \multicolumn{2}{c|}{ Group III $(n=10)$} & Value \\
\cline { 2 - 6 } & No impact (\%) & Yes (\%) & No impact (\%) & Yes (\%) & No impact (\%) & Yes (\%) & of $p$ \\
\hline Physical activity & 84.2 & 15.8 & 87.5 & 12.5 & 90.0 & 10.0 & 0.903 \\
\hline Travelling & 84.2 & 15.8 & 81.3 & 18.7 & 90.0 & 10.0 & 0.835 \\
\hline Communication & 89.5 & 10.5 & 81.3 & 18.7 & 100.0 & 0 & 0.333 \\
\hline Emotional status & 84.2 & 15.8 & 75.0 & 25.0 & 90.0 & 10.0 & 0.596 \\
\hline
\end{tabular}

Table V. Numbers of patients satisfied or dissatisfied with treatment outcomes

\begin{tabular}{|lcccc|}
\hline Variable & Group I $(n=19)$ & Group II $(n=16)$ & Group III $(n=10)$ & Value of $p$ \\
\cline { 1 - 4 } Satisfied with treatment outcomes (\%) & 68.4 & 81.3 & 90.0 & 0.379 \\
\cline { 1 - 4 } Dissatisfied with treatment outcomes (\%) & 31.6 & 18.7 & 10.0 & \\
\hline
\end{tabular}


Table VI A, B. Analysis of risk factors associated with number of patients satisfied or dissatisfied with treatment outcomes

A

\begin{tabular}{|c|c|c|c|c|c|}
\hline Variable & $\begin{array}{l}\text { Satisfied with } \\
\text { surgery results }\end{array}$ & $N$ & Mean & $\begin{array}{l}\text { Standard } \\
\text { deviation }\end{array}$ & Value of $p$ \\
\hline \multirow[t]{2}{*}{ Age } & Yes & 35 & 60.20 & 8.203 & 0.881 \\
\hline & No & 10 & 59.70 & 12.44 & \\
\hline \multirow[t]{2}{*}{ BMI } & Yes & 35 & 29.10 & 4.83 & 0.134 \\
\hline & No & 10 & 31.96 & 4.53 & \\
\hline \multirow[t]{2}{*}{ Deliveries } & Yes & 35 & 1.63 & 1.09 & 0.145 \\
\hline & No & 10 & 2.30 & 1.77 & \\
\hline \multirow{2}{*}{$\begin{array}{l}\text { Time between initial and second } \\
\text { surgery [years] }\end{array}$} & Yes & 35 & 6.51 & 5.01 & 0.007 \\
\hline & No & 10 & 13.29 & 10.47 & \\
\hline
\end{tabular}

B

\begin{tabular}{|c|c|c|c|c|}
\hline \multirow[t]{2}{*}{ Variable } & & \multicolumn{2}{|c|}{ Satisfied with surgery results } & \multirow[t]{2}{*}{ Value of $p$} \\
\hline & & Yes & No & \\
\hline \multirow[t]{2}{*}{ Previous hysterectomy } & Performed & $6(66.7 \%)$ & $3(33.3 \%)$ & \multirow[t]{2}{*}{0.393} \\
\hline & Not performed & $29(80.6 \%)$ & $7(19.4 \%)$ & \\
\hline \multirow[t]{2}{*}{ Previous perineal rupture } & Performed & $25(78.1 \%)$ & $7(21.9 \%)$ & \multirow[t]{2}{*}{1} \\
\hline & Not performed & 10 (76.9\%) & $3(23.1 \%)$ & \\
\hline
\end{tabular}

recurrent stress urinary incontinence, nowadays urologists worldwide including urologists at our center prefer minimally invasive techniques. Also, the choice of female recurrent stress urinary incontinence treatment should be individual depending on the patient's age, comorbidities, previous surgical interventions, and the patient's expectations.

\section{Discussion}

Some studies report a reoperation rate of about $8 \%$ for recurrent urinary incontinence after the initial surgery within a 5-year follow-up period [14]. The risk factors for recurrent or persistent urinary incontinence after the surgical treatment include aging, obesity, medical comorbidities, especially diabetes mellitus, incontinence severity, mixed urinary incontinence type, and previous anti-incontinence surgery [7, 15-18]. Also urge incontinence symptoms, organ prolapse severity, and being post-menopausal without hormone therapy are significant predictors for failure after the initial surgery [19]. The reasons for recur- rent urinary incontinence could include urinary bladder hyperactivity, intrinsic sphincter deficiency (ISD), urethral hypermobility, and inadequate technique of initial surgery for urinary incontinence. Most of the studies evaluating the risk factors for treatment failure after surgery for stress urinary incontinence are retrospective, poorly designed or confusing and lacking consistency in the evaluation of the results [7].

Currently, there is no consensus on how to manage failures after anti-incontinence surgery. The main reason for this conflict is the wide spectrum of anti-incontinence procedures. Repeat surgery is associated with a higher risk of intraoperative complications and lower success rate than initial surgery [5]. If there is treatment failure after the initial suburethral sling implantation, a second sling implantation is recommended; if no good result is achieved, an artificial sphincter, periurethral injections or periurethral balloon implantations are treatment options [7].

From 2003 until 2008, Burch colposuspension operation was the first choice of treatment for recurrent stress urinary incontinence at the Urology Centre of 
the Vilnius University Hospital "Santariskiu Klinikos"; however, our urologists have become more experienced in the synthetic suburethral sling implantation techniques and started treating patients by performing minimally invasive TVT or TOT procedures.

There is some evidence that the Burch colposuspension operation is less effective for recurrent stress urinary incontinence treatment if there is a suspicion of intrinsic sphincter deficiency. The TVT procedure's effectiveness for recurrent urinary incontinence has shown success rates of $71 \%$ to $82 \%$ depending on the ISD degree. The TOT procedure may not be as effective as TVT and if there is an element of ISD the success rate of the procedure is approximately $50 \%$ [20-22].

The overall success rate of suburethral sling implantation operations for recurrent urinary incontinence after the initial surgery for SUI is $60 \%$ to $78.5 \%[23,24]$. The reoperation success rate is less than the initial operation [25].

The limitations of our study include the retrospective study design, small number of patients in each group, and the fact that due to technical problems urodynamic testing was not performed in all cases. To confirm our study results, we need a well-designed prospective study with a sufficient number of patients.

\section{Conclusions}

Our study did not reveal any differences in the treatment of recurrent stress urinary incontinence outcomes by performing the Burch colposuspension operation, TOT or TVT procedures. Nevertheless, minimally invasive techniques undoubtedly have many advantages compared to the Burch colposuspension operation and nowadays TVT and TOT procedures are the first choice procedures for recurrent stress urinary incontinence treatment. Although we did not observe a statistically significant difference, in our opinion, the TVT procedure is more reasonable in obese patients and in cases of intrinsic sphincter deficiency.

The most important factors that influence the treatment results include an appropriate surgical approach taking account of the patient's risk factors, in particular obesity, sphincter deficiency, bladder hyperactivity, and proper suburethral sling implantation technique.

\section{References}

1. Nitti VW, Blaivas JG. Urinary incontinence: epidemiology, pathophysiology, evaluation, and management overview. In:
Campbell-Walsh urology. $9^{\text {th }}$ ed. Vol. III. Wein AJ, Kavoussi LR, Novick AC, et al. (eds.). Saunders Elsevier, Philadelphia 2007; 2046-78.

2. Abrams P, Cardozo L, Fall M, et al. The standardisation of terminology of lower urinary tract function: report from the Standardisation Sub-committee of the International Continence Society. Am J Obstet Gynecol 2002; 187: 116-26.

3. Shao Y, He HC, Shen ZJ, et al. Tension-free vaginal tape retropubic sling for recurrent stress urinary incontinence after Burch colposuspension failure. Int J Urol 2011; 18: 452-7.

4. Minassian VA, Drutz HP, Al-Badr A. Urinary incontinence as a worldwide problem. Int J Gynaecol Obstet 2003; 82: 327-38.

5. Sivaslioglu AA, Unlubilgin E, Keskin HL, et al. The management of recurrent cases after the Burch colposuspension: 7 years experience. Arch Gynecol Obstet 2011; 283: 787-90.

6. Cerniauskiene A. Implantation of suburethral slings for treating female urinary incontinence by retropubic and transobturatoric methods. Vilnius University Press, Vilnius, Lithuania 2012.

7. Eandi JA, Tanaka ST, Hellenthal NJ, et al. Self-reported urinary continence outcomes for repeat midurethral synthetic sling placement. Int Braz J Urol 2008; 34: 336-44.

8. Porena M, Costantini E, Frea B, et al. Tension-free vaginal tape versus transobturator tape as surgery for stress urinary incontinence: results of a multicentre randomised trial. Eur Urol 2007; 52: 1481-90.

9. Xylinas E, Descazeaud A. Repeat midurethral sling for female stress urinary incontinence after failure of the initial sling. Prog Urol 2009; 19: 590-4.

10. Ayhan A, Dogan NU, Guven S, et al. Clinical outcome of transobturator tape concomitant with vaginal hysterectomy plus anterior posterior colporrhaphy. Arch Gynecol Obstet 2009; 280: 375-80.

11. Barber MD, Kleeman S, Karram MM, et al. Risk factors associated with failure 1 year after retropubic or transobturator midurethral slings. Am J Obstet Gynecol 2008; 199: 666.e1-7.

12. Cerniauskiene A, Jankevicius F. Questionnaires for the diagnostics and treatment of female urinary incontinence and the quality of life assessment. Lithuanian Surgery 2008; 6: 11-9.

13. Shumaker SA, Wyman JF, Uebersax JS, et al. Health-related quality of life measures for women with urinary incontinence: the Incontinence Impact Questionnaire and the Urogenital Distress Inventory. Continence Program in Women (CPW) Research Group. Qual Life Res 1994; 3: 291-306.

14. Fialkow M, Gaston SR, Flum D. Reoperation for urinary incontinence. Am J Obstet Gynecol 2008; 199: 546.e1-8.

15. Subak LL, Wing R, West DS, et al. Weight loss to treat urinary incontinence in overweight and obese women. N Engl J Med 2009; 360: 481-90.

16. Rortveit G, Subak LL, Thom DH, et al. Urinary incontinence, fecal incontinence and pelvic organ prolapse in a population-based, racially diverse cohort: prevalence and risk factors. Female Pelvic Med Reconstr Surg 2010; 16: 278-83.

17. Daneshgari F, Moore C, Frinjari H, et al. Patient related risk factors for recurrent stress urinary incontinence surgery in women treated at a tertiary care center. J Urol 2006; 176: 1493-9.

18. Stav K, Dwyer PL, Rosamilia A, et al. Risk factors of treatment failure of midurethral sling procedures for women with stress urinary incontinence. Int Urogynecol J 2010; 21: 149-55. 
19. Richter HE, Diokno A, Kenton K, et al. Predictors of treatment failure 24 months after surgery for stress urinary incontinence. J Urol 2008; 179: 1024-30.

20. Jeon MJ, Jung HJ, Chung SM, et al. Comparison of the treatment outcome of pubovaginal sling, tension-free vaginal tape, and transobturator tape for stress urinary incontinence with intrinsic sphincter deficiency. Am J Obstet Gynecol 2008; 199: 76.e1-4.

21. Lovatsis D, Easton W, Wilkie D, et al. Guidelines for the evaluation and treatment of recurrent urinary incontinence following pelvic floor surgery. J Obstet Gynecol Can 2010; 32: 893-904.

22. Stav K, Dwyer PL, Rosamilia A, et al. Repeat synthetic mid urethral sling procedure for women with recurrent stress urinary incontinence. J Urol 2010; 183: 241-6.

23. Walsh CA. Recurrent stress urinary incontinence after synthetic mid-urethral sling procedures. Curr Opin Obstet Gynecol 2011; 23: 355-61.

24. Pradhan A, Jain P, Latthe PM. Effectiveness of midurethral slings in recurrent stress urinary incontinence: a systematic review and meta-analysis. Int Urogynecol J 2012; 23: 831-41.

25. Sabadell J, Poza JL, Esgueva A, et al. Usefulness of retropubic tape for recurrent stress incontinence after transobturator tape failure. Int Urogynecol J 2011; 22: 1543-7.

Received: 8.03.2013, accepted: 23.12.2013. 